\title{
STUDY OF AXILLARY AND ORAL TEMPERATURE IN A GROUP OF YOUNG ADULT AND CHILDREN
}

\author{
ABIDA AHMED ${ }^{1}$, SHAMEEMA BEGUM ${ }^{2}$, MOMOTAJ BEGUM ${ }^{2}$, MIRZA MANJURUL HAQUE ${ }^{3}$, ZAHID \\ HOSSAIN $^{4}$, ANDRINA MANISHA CHATTERJEE $^{5}$
}

\begin{abstract}
:
Background: In comparison to other bedside clinical examination basal body temperature is one of the most important indicators in establishing diagnosis of disease. Some time physiological alteration is also important and it should be kept in mind.

Materials and Methods: A total number of 246 cases were included in this study irrespective of their age and sex. This observational study was done in Mymensingh Medical College (a tertiary level institute) where study population was medical student. Materials also collected from a district orphanage.

Results: There were no significant difference in oral temperature between young adult and children. And also no significant difference of axillary and oral temperature between male and female children.

Conclusion: In this observational study there were no significant temperature difference between oral and axillary region irrespective of age and sex.
\end{abstract}

\section{Introduction:}

Recording of body temperature is an important but very common bedside clinical examination. Recording ob body temperature is a daily routine clinical examination of the physicians. Many factors influence the body temperature. For example: age is an important physiological factor that affects the body temperature.

Body temperature is of two types- Shell temperature and core temperature. Temperature of the surface of the body is called is called shell temperature and temperature of the deep tissues of the body is called core temperature. Shell temperature is measured in axilla, groin and oral cavity. Core temperature is measured in rectum. Oral temperature is said to relate closely to the core body temperature. It is determined by keeping the thermometer in mouth. Axillary temperature represent the shell temperature.

A study was done in India on axillary and oral temperature among hospitalized children and another study was also done in Srilanka on oral, axillary and rectal temperature on healthy adult subjects, but no information regarding relationship of oral and axillary temperature in normal healthy children and in young adult is available. In children there is increased metabolism, therefore it may be assumed that children may have higher body temperature than the adult.

Therefore this study has been designed to study the axillary and oral temperature in children and oral temperature in young adult and to compare these values between children and adult. This study was also set up for comparison of oral and axillary temperature in children and in adult with that of other countries. ${ }^{1-4}$

\section{Materials and Methods:}

A total number of 100 children were included in this study. Of them 60 were male and 40 were male In this study children were between the ages of 6 years and 15 years and the mean age were 10.3 years. The children were selected from an orphanage in Mymensingh town and also from the local area of this town. The purpose of the study was explained to the children and their guardians. Temperature was recorded by clinical thermometer. The children were allowed to wear light cotton cloths. Before measuring the axillary temperature, axilla was mopped by tissue paper. It was also ensured that the children had not consumed any food (solid or liquid) that could have transiently altered the oral temperature, at let 20 minutes prior to the

1. Professor, Department of Physiology, Comilla Medical College

2. Assistant Professor, Department of Physiology, Dhaka Medical College

3. Associate Professor, Department of Paediatrics, CBMC,B

4. Assistant Professor, Department of Physiology, MAG Osmani Medical College, Sylhet

5. Student of M. phil Physiology in Dhaka Medical College 
measurement of the temperature. The thermometer was kept under the tongue as far back as possible and the subjects were instructed to close their lips taking care not to bite the thermometer. It was placed deep in the right axillary fold and the arm was firmly held down to measured the axillary temperature. The arm was held close to the body of the subjects. In both axilla and oral cavity the thermometer was kept for about 2 minutes. These readings were recorded at 1 -minute interval until a constant reading was obtained. Then the averages of three readings were taken as axillary and oral temperature.

A total number of 146 young adult were included in this study. Of them 82 were male and 64 were male. They were between the ages of 19 years and 22 years and the mean age were 21 years. The study population were the medical students of Mymensingh Medical College. The thermometer was kept under the tongue as far back as possible and the subjects were instructed to close their lips. The thermometer was kept for about 2 minutes. These readings were recorded at 1-minute interval until a constant reading was obtained. Then the averages of three readings were taken as oral temperature.

Table I

Distribution of study population:

\begin{tabular}{lccc}
\hline & Group A & \multicolumn{2}{c}{ Group B } \\
Male & Female & Male & Female \\
\hline $\mathrm{N}=82(56.2 \%)$ & $\mathrm{N}=64(43.8 \%)$ & $\mathrm{N}=60(60 \%)$ & $\mathrm{N}=40(40 \%)$ \\
\hline \multicolumn{4}{c}{ Table II } \\
Mean \pm SE & Of Oral Temperature In Group A (In \\
group A)
\end{tabular}

Grouping: Total population were grouped as group A and group B. Both groups were again sub- grouped into male and female.

\section{Results:}

Results of body temperature were expressed in Fahrenheit. Result were shown in table:I, II, III, IV, V, VI. study population in children were 100, 60 were male and 40 were female. Adults were 146 in number. Mean $\pm \mathrm{SE}$ of oral temperature in young adult male were $98 \pm 0.061$ and in young adult female were $98.066 \pm 0.075$. Oral temperature in Male children were $98.83 \pm 0.05$ and in female were $98.75 \pm$ 0.03 degree Fahrenheit. In children axillary temperature were $97.73 \pm 0.04$ degree Fahrenheit in male and in female were $97.93 \pm 0.02$ degree Fahrenheit. There were no significant difference in oral temperature between young adult and children. In children there were no significant difference of axillary and oral temperature between male and female children. In children there were very limited degree of correlation $(p=0.75)$ between oral and axillary temperature.

\section{Table III}

Mean \pm SE Of Oral And Axillary Temperature In Group B

\begin{tabular}{lccc}
\hline Temperature & Sex & Mean & SE \\
\hline Oral & Male & 98.83 & 0.05 \\
& Female & 98.75 & 0.03 \\
Axillary & Male & 97.73 & 0.04 \\
& Female & 97.93 & 0.02 \\
\hline
\end{tabular}

Table IV

Students " $t$ " test showing difference of body temperature in group A

\begin{tabular}{lllll}
\hline Body temperature & Sex & Frequency & Mean \pm SE & "P” Value \\
\hline Oral Temperature & Male & $\mathrm{N}=82$ & $98.154 \pm 0.061$ & $>0.05 \mathrm{NS}$ \\
& Female & $\mathrm{N}=60$ & $98.066 \pm 0.075$ & \\
\hline
\end{tabular}


Table V

Students " $t$ " test showing difference of body temperature in group B (In children)

\begin{tabular}{lllll}
\hline Body temperature & Sex & Frequency & Mean \pm SE & "P” Value \\
\hline Axilary Temperature & Male & $\mathrm{N}=60$ & $98.83 \pm 0.05$ & $>0.05 \mathrm{NS}$ \\
& Female & $\mathrm{N}=40$ & $98.75 \pm 0.03$ & \\
Oral Temperature & Male & $\mathrm{N}=60$ & $97.73 \pm 0.04$ & $>0.05 \mathrm{NS}$ \\
& Female & $\mathrm{N}=40$ & $97.93 \pm 0.02$ & \\
\hline
\end{tabular}

Table VI

Correlation between oral and axillary temperature in children

\begin{tabular}{llll}
\hline Body temperature & Mean.08 \pm SE & "P"Value & Remarks \\
\hline Axilary Temperature & $98.83=0.05$ & 0.75 & Very limited degree of positive \\
Oral Temperature & $97.83=0.054$ & & correlation \\
\hline
\end{tabular}

\section{Discussion:}

This study was designed to determine the body temperature in children and adult and to compare these values between them. This study was also set up for comparison of body temperature of children and adult in Bangladesh with that of other countries. For this purpose, 246 study population were selected. Among them 146 were adult and 100 were children.

Specification of the clinical thermometer was WE, CHINA, H.C. 97, CV. Though in usual practice it was claimed that the thermometer took about 0.5 to 1 minute for reading a constant temperature, we kept that for 2 minutes as suggested by K.M.H Pera et al. Children below the age of 5 years were excluded from the study as the oral temperature could not be determined because of the potential risk of injury from the child biting the thermometer as observed by K.M.H Perara, G.R Columbage and Chandrica Perera. ${ }^{1}$ Psychologically children are not capable of realizing this facts. ${ }^{5}$ Oral temperature recording is some troublesome in children. Children have less immunity than the adult. Therefore, it is not safe for the children to measure the oral temperature.

Whenever a child is asked to open his/her mouth for putting the thermometer into the mouth under the tongue, sometimes the children become non cooperative and do get frightened. There is also a risk of biting thermometer. But it is very easy to introduce the thermometer into the axilla in children. On the other hand it is somewhat easier to measure the oral temperature in adult. In our study undergraduate medical students were included. They felt uneasy in the measurement of axillary temperature. Therefore in adult only the oral temperature was measured. Oral temperature in adult and children were compared. This comparison was done to assume the variation of oral temperature in children and adult, so that we can take the oral temperature in adult as an important indicator of body temperature. But in children it is easier and safe to measure the axillary temperature. Therefore in children correlation between oral and axillary temperature were calculated to establish specific relation between oral and axillary temperature. But in our study there were very limited degree of correlation between oral and axillary temperature. Therefore we may also take the axillary temperature in children as an important area of measurement of body temperature.

In this study there is increased body temperature in children than in adult. Our result is in agreement with that of William F.Ganong, 2005. ${ }^{6}$. They stated that children have more metabolic activity than the adult. Body temperature is related with metabolic activity of the body, more is the body metabolism, more is the body temperature. In children there is increased metabolism. Therefore, Children have more body temperature than the adult. 
There were no significant difference of oral temperature in young adult male and female students. This result can be explained according to William F.Ganong, 2005. ${ }^{6}$ They stated that female have higher basal body temperature than the male during ovulation. But in our study basal body temperature were not measured and also the possible dates of ovulation were not assumed by personal history. Therefore oral temperature in young adult male and female students were same. However further study about the basal temperature in young adult male and female may clarify this relationship.

\section{References:}

1. Perera KMH, Colombag GR, Perera C. Axillary teperature in relation to oral temperature in a group of children in Sri Lanka . Ind J Pharmac 1981; 35: 26-31.
2. Collumbine H. Oral rectal and axillary temperature of adult Ceylonese. Ceylon J. Med Sci 1949; 6:1-3.

3. Ghai CL. Body temperature . In: A text book of practical Physiology. $4^{\text {th }}$ edition. India. Jaypee Brothers, 1990: 243-249.

4. Roy RN. Body temperature measurement. In: Viva and practical Physiology, Biochemistry and Biophysicas. $1^{\text {st }}$ edition . Calcutta : Books and Allied (P) LTD 1998: 331.

5. Morgan, Hungher JO and Bangham JA . Preinduction behavior of children - A review of Placebo-controlled trails of sedatives. J. Anaes 1990: 45: 427-435.

6. William F.Ganong. Central regulation of visceral function : temperature regulation. In: Review of Medical Physiology. 21 ${ }^{\text {st }}$ edition: Stamford: Appleton and Lange, 239-241. 